\title{
Pedro Vicente Cañete: un ilustrado criollo contrarrevolucionario en Charcas (1808-1814)
}

Pedro Vicente Cañete: An Enlightened Counterrevolutionary Creole in Charcas (I808-18I4)

DOI: $10.22380 / 20274688.312$

Recibido: 17 de julio del 2017

Aprobado: 6 de octubre del 2017
VÍCTOR PERALTA RUIZ

Consejo Superior de Investigaciones Científicas, Madrid, España

victor.peralta@cchs.csic.es

Orcid: 0000-0002-5170-7415

ALFREDO MORENO CEBRIÁN

Consejo Superior de Investigaciones Científicas, Madrid, España

alfredo.moreno@cchs.csic.es

Ordic: 0000-0002-4098-2104

$\leftrightarrow \quad R E S \quad U M E N$

Este trabajo aborda la trayectoria política jurídica y política con los ideólogos de de un ilustrado criollo, el abogado Pedro Vicente Cañete, y su oposición a los procesos autonomistas que estallaron en Montevideo, Charcas, La Paz y Buenos Aires en el marco de la crisis de la monarquía hispánica de 1808. Se argumentará que Cañete fue uno de los escasos ilustrados fidelistas implicados en una contienda las revoluciones hispanoamericanas. Su doctrina regalista se basó en una lectura de la realidad que cuestionaba el que una junta de gobierno provincial pudiera ser depositaria temporal de la majestad real, en calidad de pueblo soberano, y que, con ese pretexto, pudiera imponer su jurisdicción a la Audiencia de Charcas.

Palabras clave: Ilustración, regalismo, Alto Perú, Pedro Vicente Cañete, contrarrevolución. 
This article deals with the political trajectory of an enlightened creole, the lawyer Pedro Vicente Cañete, and its opposition to the autonomist processes that erupted in Montevideo, Charcas, La Paz and Buenos Aires in the context of the crisis of the Hispanic monarchy which broke out in May 1808. We argue that Cañete was a scarce representative of the Enlighten-

ment implicated in a juridical-political contest against the ideologues of the Hispanic American revolutions. His regalist doctrine was based on a reading of reality that questions that a provincial Junta could be the temporary custodian of the royal majesty in condition of a sovereign people; and with that pretext, could impose its jurisdiction to Charcas.
\end{abstract}

Keywords: Enlightenment, regalism, Alto Perú, Pedro Vicente Cañete, counterrevolution.

\title{
Introducción ${ }^{1}$
}

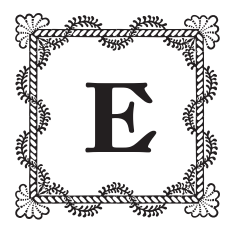

l vínculo entre Ilustración y revolución en Hispanoamérica se constituyó por décadas en una de las temáticas más trabajadas por los investigadores desde las perspectivas filosóficas, políticas e ideológicas. Una de las conclusiones más importantes de este polémico asunto es que no existe una exclusiva relación de causaefecto entre ambos fenómenos, es decir, que no es posible postular unos orígenes ilustrados de las independencias ni tampoco que los hombres de la Ilustración se desentendieron por completo de los procesos revolucionarios (McFarlane; San José). Una importante propuesta teórica reciente ha sugerido entender geográficamente la Ilustración e introducir en el debate no solo respuestas para qué fue y cuándo ocurrió, sino también para dónde transcurrió (Withers).

La Audiencia de Charcas es un ineludible laboratorio de análisis para observar la importancia de la difusión geográfica de la Ilustración a fines del

I Investigación realizada dentro del proyecto I+D HAR2015-67197-R, "Cambios e innovaciones sociales: España y el Perú de la crisis del imperio transoceánico al Estado liberal”, financiado por el Ministerio de Economía y Competitividad de España. 
siglo XVIII y principios del XIX. En instituciones de este territorio como la Academia Carolina y la Universidad Francisco Javier se cultivó la generación ilustrada más relevante en el ámbito jurídico a la vez que comprometida políticamente, al punto que varios de sus exalumnos integraron las juntas de gobierno de La Plata de i8o9 y Buenos Aires en i8ro (J. Mendoza; Thibaud). Destaca igualmente la participación de una parte de estos ilustrados charqueños en la asamblea constituyente de Tucumán en I8I6 que dio origen a la nación argentina (Irurozqui, "La telaraña”). Pero la politización de los ilustrados charqueños no solo se constriñó al ámbito de los que abrazaron el proyecto autonomista e independentista, sino también a aquellos que decidieron utilizar sus argumentaciones jurídicas para defender la fidelidad a la monarquía en la coyuntura de crisis abierta en I8o8.

Tal fue el papel asumido por autoridades como el intendente de Potosí Francisco de Paula Sanz, el arzobispo Benito María Moxó y Francolí o el abogado y asesor Pedro Vicente de Cañete. Así, Charcas, en su condición de administración anexada al Virreinato del Perú desde i8ıo, sería el escenario de una contienda discursiva y bélica entre ilustrados revolucionarios y contrarrevolucionarios que, ocasionalmente, se produjo en otras realidades hispanoamericanas (López; Silva). En el caso del personaje objeto del presente estudio, el discurso ilustrado y regalista sustentó su lenguaje contrarrevolucionario tras la crisis monárquica de 1808 .

Pedro Vicente Cañete (Asunción, I749 - Chuquisaca, I8I6) es un personaje cuya trayectoria se asocia a su producción en el terreno del derecho (el Sintagma de las resoluciones prácticas cotidianas del Real Patronazgo de las Indias, Potosí, I783, y el Código carolino de ordenanzas reales de las minas de Potosí, Potosí, I794) y de la historia (la Guía histórica, geográfica, física, politica, civil y legal del gobierno de la intendencia de la provincia de Potosí, Potosí, 1789)². Más recientemente se ha discutido en torno a la polémica que, en su condición de asesor del intendente de Potosí, Francisco de Paula Sanz mantuvo con el fiscal de la Audiencia de Charcas, Victorián de Villava, autor de un "Dictamen sobre la abolición de la mita de Potosí”. Cañete se opuso al "Dictamen” de Villaba y propuso una nueva mita basada en un incremento forzado de comuneros

2 Estos aspectos en su trayectoria biográfica fueron estudiados por Martiré; Mariluz, "Estudio preliminar” y Cebrián 691-699.

3 Dictamen reproducido en Portillo, La vida atlántica.

70 VOL. 23, N. 1. PP. 68-96, ENERO-JUNIO DE 2018

$\begin{array}{lllllllllllllllllll}\text { F } & \mathbf{R} & \mathbf{O} & \mathbf{N} & \mathrm{T} & \mathbf{E} & \mathbf{R} & \mathbf{A} & \mathbf{S} & d e & \text { la } & \text { H I } & \mathbf{S} & \mathbf{T} & \mathbf{O} & \mathbf{R} & \mathbf{I} & \mathrm{A}\end{array}$ 
indígenas a dicho centro minero para beneplácito de los azogueros (Buechler; Lorandi; Portillo, "Victorian de Villava"; Tandeter).

Como complemento de los trabajos arriba reseñados, este artículo se concentra en la actuación política, ideológica y militar de Cańete durante la coyuntura experimentada por las administraciones de la América meridional, como consecuencia de la crisis en que quedó subsumida la monarquía hispánica a partir de mayo de 1808. La trayectoria política de Cańete fue resumida por Mariluz Urquijo como la de un "fidelista descentralizador" que, en sus palabras, entronca con el contrarrevolucionario criollo que atizó con su retórica las históricas fuerzas centrífugas y opuestas entre los territorios de Charcas y el Río de la Plata para dividir el proyecto independentista liderado por este último (Mariluz, "El fidelismo").

En este trabajo se argumentará que Cañete combatió a la Junta de Gobierno bonaerense, y a todos los autonomismos previos y posteriores a ella, por atentar, con la supuesta retroversión de la soberanía real al pueblo, contra el principio regalista de que su ejercicio era potestad exclusiva de los virreyes y de los presidentes de Audiencia. Cañete sostuvo además que el gobierno establecido en Buenos Aires en mayo de I8Io, por su carácter de junta provincial, no lo autorizaba a someter o anexionar a la Audiencia de Charcas a su tutela territorial. Se procurará demostrar la complementariedad de ambos axiomas jurídicopolíticos de Cañete, a través del estudio de su polémica actuación discursiva y práctica con relación a la Junta de Gobierno de Montevideo (I808), las juntas de gobierno de La Plata y la Paz (I809), la Junta de Gobierno de Buenos Aires (I8Io) y, por último, la guerra civil del Alto Perú entre I8ıo y i8I4. Este análisis se sustentará en sus múltiples escritos, tanto editados como inéditos, además de la documentación que sobre la actuación de este personaje se conserva en el Archivo General de Indias.

\section{El ideólogo contrarrevolucionario entre 1808 y 1810}

Entre Cañete y los oidores de la Audiencia de Charcas se iba a producir una creciente tensión durante los años de la presidencia de Ramón García de León 
y Pizarro (1797-1809). El motivo del conflicto se debió a que Pizarro confió a la asesoría de Cañete la recuperación de sus prerrogativas cortesanas sobre los oidores en los ceremoniales públicos ${ }^{4}$. Esta ofensiva provocó un profundo malestar en estos últimos y por ello los oidores procuraron encontrar la ocasión para deshacerse del ilustrado asunceño. La oportunidad les llegó cuando, por asuntos particulares, Cañete emprendió un viaje a Potosí. Los oidores, aprovechando esta circunstancia, publicaron el 2I de abril de 1808 el decreto de su extrańamiento de Chuquisaca por diversos cargos dolosos (René-Moreno I35). Ante este imponderable, Cańete reasumió interinamente su puesto de asesor del intendente Francisco de Paula Sanz, cargo que había ejercido entre I784 y I803.

Su suerte pareció cambiar a mediados de 1808 cuando conoció al emisario de la Junta de Sevilla, el brigadier peruano José Manuel de Goyeneche, quien desde ese momento le brindó su amistad y protección. A través de este militar, Cañete logró contactar al virrey del Río de la Plata, Santiago Liniers, con el propósito de que mediara en su reposición como asesor en la ciudad de La Plata. Sin embargo, ninguno de los oficios en su favor cursados por esta autoridad a la Audiencia hizo cambiar el parecer de los oidores.

Fue en esas circunstancias personales adversas para Cańete cuando la crisis de la monarquía hispánica produjo la primera fractura en el virreinato rioplatense. La plaza de Montevideo, por decreto de su gobernador, Francisco Javier Elío, se constituyó en una junta de gobierno protectora de los derechos de Fernando VII el 2I de septiembre de I808. Esta decisión fue desaprobada y combatida por las autoridades de Buenos Aires. Pero el virrey rioplatense iba a experimentar nuevas adversidades relacionadas con su supuesta simpatía por la causa bonapartista que lo debilitaron como gobernante. El alzamiento autonomista en Buenos Aires de Martín de Alzaga en enero de 1809, a pesar de haber sido abortado, debilitó aún más su poder. En el transcurso de aquel conflicto, desde Potosí Cañete se sumó a la causa de Liniers y por iniciativa personal redactó una "Carta consultiva apologética" contra el juntismo de Montevideo, documento que concluyó el 25 de enero de 1809 ".

La "Carta consultiva apologética" apoyó la vista fiscal de octubre de I808, firmada por los fiscales Villota y Caspe, en la que se declaraban infundadas las acusaciones del gobernador de Montevideo contra el virrey por su supuesta

4 Sobre la evolución e importancia de los poderes cortesanos en Charcas colonial, véase Bridikhina.

5 Este escrito posiblemente fue pensado por Cañete para reforzar su pretensión a la plaza de oidor de la Real Audiencia de Buenos Aires (Mariluz, "El fidelismo” I82).

72 VOL. 23, N. 1. PP. 68-96, ENERO-JUNIO DE 2018

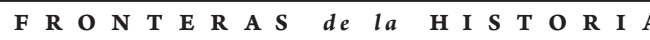


dejación hacia la causa fidelista debido a su origen francés. Cañete defendió la gestión del virrey ante la crisis y afirmó, rotundamente, que en ninguna de las actuaciones de este se deslizó "el reconocimiento del Emperador de la Francia por soberano de España" (Cañete, "Carta consultiva apologética" 75).

No bastándole ello, en seguida enfiló contra la Junta montevideana por excederse en un patriotismo que calificó de intempestivo y mal entendido, porque "ha producido el cisma, el mal ejemplo y el escándalo, en vez de fijar la paz, la concordia y la unidad, que indudablemente debieron proponerse" (Cañete, "Carta consultiva apologética" 68).

Su principal argumentación contra Montevideo, discurso que mantendría a lo largo de su combate jurídico-político con otras manifestaciones del autonomismo, consistió en diferenciar la justificable reacción juntista en la península ibérica en 1808 con la inútil pretensión de activarla en Hispanoamérica. A su entender esto último no era concebible, en la medida en que la autoridad de los virreyes seguía estando respaldada por su condición de alter ego del monarca. De la mortal herida inferida a este tradicional principio de la delegación del poder en la monarquía, Cañete culpó al Gobierno de Montevideo, porque "en la América es ley fundamental, en el título de los Virreyes, de que estos supremos magistrados hayan de ser los vicarios del Príncipe Soberano, con la representación de viva imagen suya" "Carta consultiva apologética" 82).

El escrito de Cañete, que fue conocido por el gobernador rebelde Francisco Javier Elío, mereció una respuesta de esta autoridad montevideana. El líder juntista se explayó en rebatir la mayor parte de los 59 razonamientos en que estuvo dividida la "Carta consultiva apologética", a la que calificó de contener "adulaciones bajas, algunas mentiras y hermosos rasgos de historia antigua profana, bellas y exactas comparaciones de Scipion con Liniers (ahí es una friolera)" ("Reflexiones de Francisco Javier Elío" 36). El pasaje más importante de esta respuesta se halla en el rechazo al razonamiento 20, en el que Elío se reafirma en que la actuación fidelista de Liniers durante la visita del emisario de Bonaparte, el marqués de Sassenay, fue cuestionable:

[...] el documento II, que cita el apologista [Cañete] será uno de los mayores cargos que deberá tener el Señor Virrey y principalmente la retardación de la proclamación de Fernando y que el cabildo de Buenos Aires jamás acordó fue indebida y maliciosa, y el ocultar a los pueblos más fieles los motivos, es el mayor agravio a su fidelidad. ("Reflexiones de Francisco Javier Elío" 40) 
Elío culminó sus reflexiones enfilando directamente contra los antecedentes de Cañete, a quien recordó su separación a fines del siglo XviII del cargo de fiscal asesor de Potosí por cohecho y, luego, su transformación en un oportunista adulador del virrey Liniers debido a su aspiración de obtener un empleo. Cañete no respondió.

Para las aspiraciones burocráticas de Cañete fue un duro revés la destitución de Liniers dispuesta por la Junta Central, aparentemente en represalia por su entrevista con Sassenay, y su reemplazo por Baltasar Hidalgo de Cisneros en julio de I809. En esa coyuntura, en La Plata se había producido el 25 de mayo de I809 la formación de la primera Junta de Gobierno liderada por la Audiencia.

Aunque Cañete no resultó directamente perjudicado por la destitución del presidente García Pizarro, al no hallarse en la capital por seguir vigente su exilio potosino, su protagonismo volvió a relucir cuando decidió enfrentarse a la Junta de Gobierno charqueña. Con este propósito hizo circular a mediados de I809 un manuscrito titulado "Espectáculo de la verdad", con el que se propuso desmentir un folleto anónimo titulado Observaciones, discursos y sentimientos del vecindario fiel de La Plata. En este escrito se responsabilizó por igual al virrey Liniers, al presidente García Pizarro, al arzobispo Moxo, al brigadier Goyeneche y al asesor Cañete de simpatizar con la conjura carlotista. Cañete señaló que esa acusación fue en realidad un embuste urdido por los oidores, quienes a través de pasquines

[...] malarmaron al pueblo bajo de cuerda que para entregar estos dominios a la Corona de Portugal se estaba procesando a los vecinos más honrados [...] y como lograron inspirar desconfianza verdadera o fingida a los canónigos, regidores y vecinos más poderosos que tenían la masa en la mano para recoger prosélitos fue muy fácil armar la borrasca por medio de hablillas y susurraciones sediciosas. (Cañete, "Espectáculo" cXliv)

De esta afirmación se desprende que Cañete no solo cuestionó las causas de la existencia de la Junta de Gobierno, sino también que esta utilizase a los sectores populares para acceder al poder y preservarse en este. Cañete activó así uno de los principales componentes de su actitud ilustrada que fue el repudio a la participación del pueblo en los asuntos relacionados con el ejercicio de la soberanía.

El "Espectáculo de la verdad" siguió la línea de reflexión de la "Carta consultiva apologética" en lo que se refiere a denunciar la violación de la tradición 
legal hispana por parte de los juntistas charqueños ${ }^{6}$. Tratados estos por Cañete como "malévolos" e "ignorantes", también los acusó de haber incurrido en un delito de lesa majestad al conspirar y apresar a un mandatario nombrado por el rey. Haciendo una alegoría paternalista, defendió que la Audiencia y el pueblo eran "como hijos obedientes respecto de los Virreyes y Presidentes" y no podían tener jurisdicción ni imperio sobre ellos: "si por desgracia fueren [estos últimos] fanáticos o tiranos no pueden hacerse jueces de sus Jefes y cabezas sino solamente poniéndolos en resguardo de honor dar cuenta al Rey con justificación de los hechos para que ponga remedio" (Cañete, "Espectáculo" CLII).

Al no procederse de este modo, dictaminó que la Audiencia había provocado un vergonzoso trastorno de consecuencias funestas, y profetizó que en ese camino al precipicio "mucho falta que ver, y en el entretanto todo hombre de bien debe examinar los hechos en este espectáculo de la verdad" (Cañete, "Espectáculo" CLII). Cañete pronto comprendería que las motivaciones de los juntistas no solo se explicaban por celos protocolarios locales, sino también que "trascendían el espacio charqueño en la medida que eran expresión de la desobediencia altoperuana a la autoridad virreinal del Río de la Plata" (Irurozqui, "Del acta" 204-205).

El experimento autonomista de La Plata pronto se contagió a la intendencia de La Paz, cuyo vecindario, el I6 de julio de i809, constituyó una junta tuitiva de los derechos de Fernando VII. Esta decisión se produjo en momentos en que, en el Río de la Plata, el virrey Hidalgo de Cisneros trató infructuosamente de controlar la situación charqueña al decidir el reemplazo de García Pizarro por el general Vicente Nieto. La complicación de la crisis con el contagio del autonomismo paceño a otras realidades se tornó inmanejable, a pesar de las represalias de Nieto. Por ese motivo, el virrey del Perú, José Fernando de Abascal, tomó la decisión de invadir con su ejército, comandado por el brigadier Goyeneche, una administración que hasta 1776 había estado bajo jurisdicción peruana. En octubre, cuando se produjo este hecho, Cañete, con el apoyo del intendente de Potosí, transmitió a Goyeneche "importantes avisos políticos para la ocupación de aquella ciudad [La Paz]” (G. Mendoza 48).

Cañete celebró tanto el retorno de Goyeneche como el aplastamiento militar de las rebeliones paceña y charqueña que pareció devolver la tranquilidad a la Audiencia. A principios de i8ıo, se ganó la confianza de Nieto y se 
convirtió en su consejero predilecto. Cañete aprovechó esta circunstancia para, a través de aquel, convencer al virrey de nombrarlo oidor interino en Buenos Aires. Pero el io de febrero de i8ıo el virrey desaprobó esta candidatura (Mariluz, "El fidelismo" I86). No obstante este revés, Cañete fue convocado por el virrey para que le redactara un dictamen legal que orientara su actuación ante la crisis monárquica y, sobre todo, tranquilizar a los criollos que se mostraban dispuestos a relevarlo.

El "Dictamen a pedimento del Excmo. Sr. Virrey" fue concluido por Cañete el 26 de mayo de i8ıo, es decir, un día después del estallido en Buenos Aires de la Revolución de Mayo que depuso a Hidalgo de Cisneros y estableció la Junta Provisional Gubernativa de las Provincias del Río de la Plata a nombre del señor don Fernando VII. El "Dictamen", posiblemente, arribó a la capital en junio y las autoridades autonomistas decidieron publicarlo el 3 de julio de I8ro en la Gaceta de Buenos Aires como prueba de la perfidia anticriolla de Cañete. El "Dictamen", prácticamente desconocido por los autores que se han ocupado de su biografía, fue una pieza clave de su pensamiento doctrinario porque propuso una fórmula política transitoria para que los cuatro virreinatos hispanoamericanos (Nueva España, Río de la Plata, Nueva Granada y Perú) actuaran conjunta y solidariamente en caso de la total pérdida del reino por obra de Napoleón Bonaparte.

La primera premisa del "Dictamen" apuntó a que, por la falta de ilustración y disciplina en las costumbres, así como por no existir fraternidad entre las familias políticas y los pueblos, "no está la América en estado de organizar una política sutil que pudiera servir de matriz para un sistema original de gobierno" (Cañete, "Dictamen" 4). Cañete avizoró la imposibilidad de conformar en Hispanoamérica una instancia soberana centralizada, similar a la Junta Central, como producto de la reunión de las juntas provinciales, porque era imposible que se reunieran unos pueblos y familias que habían vivido siempre aislados unos de otros. Puso como ejemplo a Buenos Aires, que en caso de asumir el depósito de la autoridad soberana a través de una junta no podría someter a los pueblos del Alto Perú "que intentarán fijarla [el depósito de la soberanía real] en el centro de sus serranías”. De ahí pronosticó que, como consecuencia del choque de ambas pretensiones, empezaría una guerra civil de la cual se aprovecharía "cualquiera potencia europea, o la del Norte de América [que] se apoderaría de su gobierno facilísimamente con todas esas inmensas propiedades" ("Dictamen" 5).

Descartada por imposible la opción de una suprema instancia juntera, la segunda premisa asumida por Cañete fue hacer consciente a Hidalgo de Cisneros 
de que, como alter ego del monarca, debía emprender con los otros virreyes hispanoamericanos una reacción política similar a la ocurrida en la Península en caso de perderse España. En concreto, se debía constituir un único gobierno provisional absoluto

[...] mientras los cuatro virreyes de ambas Américas acuerden entre sí a la mayor brevedad la convocación de Cortes en un punto promediado a tan grandes distancias que sea accesible a todos los Diputados, a fin de que [...] se proceda al nombramiento de una Regencia Soberana que represente los derechos, la Autoridad y la Persona del Sr. D. Fernando VII. ("Dictamen" 6)

Entretanto, recomendó a Hidalgo de Cisneros que en el propio Buenos Aires conformara inmediatamente una junta general, "muy secreta de todas las autoridades de la capital donde se acuerde bajo del más solemne juramento conservar la debida obediencia al Sr. Virrey como cabeza del Reyno y Vicario único del Soberano". Asimismo, consideró que en caso de consolidarse el dominio de la dinastía Bonaparte en España con la disolución de la Regencia y las Cortes, tal junta general debía transmitir todo el poder real al virrey, en tanto que lo propio debía verificarse en todas las cabeceras de las provincias y cabildos del Río de la Plata, "debiendo todos tener entendido que el Sr. Virrey queda autorizado como lo estaba nuestra Suprema Junta Central para conferir empleos, distinciones y rangos a los beneméritos con la misma firmeza que sí el Rey por sí mismo lo hiciera" ("Dictamen” 7).

La tercera premisa de Cañete estuvo relacionada con la forma en que el virrey, una vez legitimado con los máximos poderes soberanos en Buenos Aires, debía actuar en el Alto Perú. Con el propósito de impedir la fractura de las soberanías patrias recomendó a aquella autoridad que

[...] para no excitar celos peligrosos se puede anunciar al Perú que la silla del gobierno reside por ahora en Buenos Aires como un antemural contra las invasiones enemigas, para que sirva de dique que reprima la inundación hacia lo interior de estas provincias: fijándoles prudentemente la esperanza de que en mejor oportunidad se reconcentrará el poder nacional en las montańas de los Andes. ("Dictamen" 8-9)

Cañete concluyó que si durante la crisis que se avecinaba el virrey obraba con prudencia y firmeza, se lograría evitar dos alternativas deseadas por los ingleses que eran, 
[...] o bien su protección para provocarnos a la independencia; o bien el gobierno de Regencia al cargo de la Serenísima Señora Infanta de España Princesa del Brasil Da. Carlota de Borbón como llamada al trono en las Cortes de 789 a falta de los SS Infantes sus hermanos. ("Dictamen" 9)

Cañete, en su "Dictamen", consideró que la alternativa carlotista tenía el peligro de que la Corona portuguesa adujera la definitiva apropiación de estos establecimientos ultramarinos, fundándose para ello en el Tratado de Fontainebleau, "a cuyo efecto podría entrar con el título aparente de Regencia para señorearse después con dominio absoluto". No obstante, ante la disyuntiva de adoptar una de las dos opciones, Cañete prefirió el carlotismo, siempre que la infanta respetara a los magistrados, jefes y ministros nombrados por su hermano cautivo.

La publicación del "Dictamen" por parte de la Junta bonaerense tuvo el propósito de mostrar el desprecio expresado por Cańete hacia el pueblo, al que consideraba carente de virtudes. Este comentario anónimo, añadido inmediatamente después de publicado el documento, resaltó la hipocresía de un magistrado que durante su trayectoria nunca se preocupó por educar a los súbditos. El segundo motivo de la publicación fue desacreditar la autoridad del virrey destituido. Si este se hubiera mantenido en el cargo, grande era la posibilidad de que hubiese aplicado las recomendaciones de Cañete "para que se perpetúe en un mandato indebido y notoriamente ilegítimo" ("Dictamen” II). La réplica gubernamental al "Dictamen" concluyó con la reproducción a su vez del dictamen del fiscal de la Audiencia de Charcas, Victorián de Villava, del I6 de septiembre de I80o, contra Cañete, por actos de cohecho, falsedades y falta de integridad personal durante su etapa como asesor en Potosí (Portillo, "Victorián de Villava").

Una vez apartado el virrey del escenario político, con su destitución y destierro, Cañete pasó a convertirse en el detractor de la Revolución de Mayo a quien por cualquier medio se debía neutralizar (Pérez). En las instrucciones confidenciales a Juan José Castelli, jefe de la primera expedición militar rioplatense al Alto Perú, la Junta especificó que era una prioridad la captura y remisión a Buenos Aires de Cañete. Tras la victoria de Castelli sobre las tropas realistas en la batalla de Suipacha el 7 de noviembre de I8ro, fueron hechos prisioneros y luego fusilados el presidente Nieto y el intendente Paula Sanz. Cañete, tras conocer la derrota, comentó: 
[...] yo salí de Potosí entre los funestos torbellinos del tumulto popular el año de 8Io, cuando el gobernador fue arrestado para el patíbulo, y tuve que arriesgar mi vida con mi marcha precipitada por el despoblado de la costa, sin equipaje ni comidas [...]. (AGI, D, 3, "Pedro Vicente Cañete haciendo relación de sus esfuerzos por la causa realista, I813")

En su huida, supo que Castelli había decretado la pérdida de su empleo y la confiscación de sus bienes (Mariluz, "El fidelismo" I86). Como resultado de su exilio temporal en Tacna, un poblado al sur del virreinato peruano, se iba a iniciar una nueva etapa en la trayectoria contrarrevolucionaria de este abogado que le haría abandonar su papel de mero combatiente ideológico.

\section{Combatiente y propagandista contrarrevolucionario (1811-1813)}

Instalado en su refugio tacneño, Cañete entró en contacto tanto con el virrey Abascal como con el brigadier Goyeneche, presidente de la Audiencia del Cuzco, y los mantuvo informados de los sucesos altoperuanos. Lo que le sorprendió fue la inusitada discusión política entre la población que giraba en torno a apoyar o no la Revolución de Mayo. Cañete describió ese escenario como el de un "grosero y poco ilustrado vecindario", seducido por los numerosos impresos y manuscritos llegados de Buenos Aires con sus opiniones antimonárquicas. Por eso, decidió enfrentar el problema con la circulación de una serie de escritos fidelistas que, paradójicamente, un juez confiscó y hasta hizo todo lo posible por alejarlo del poblado. No obstante, Cañete atribuyó a sus proclamas y a su catecismo político la contención de un tumulto que estuvo a punto de estallar en Moquegua:

[...] pero como no quedó desarraigada la cizaña, se sublevó el pueblo de Tacna el 20 de julio de 8II a los cuatro meses siguientes de mi salida por los nuevos dogmatizadores que encendieron el fuego de la sedición, 
mientras yo me incorporé con el ejército real del Desaguadero por llamamiento del Señor Gral. Goyeneche. (AgI, $D, 3)^{7}$

De lo anterior se desprende que entre noviembre de i8Io y marzo de I8II Cañete desempeñó a plenitud un papel de propagandista contrarrevolucionario, en desmedro de su predicamento doctrinario, para dirigirse a los pueblos. Dos de sus primeros pasquines fueron los firmados en Tacna el I3 de diciembre de I8Io con los títulos de los "Peruanos leales del Collado" y los "Soldados del Perú”. El primero quiso persuadir a los habitantes de Chuquisaca de no seguir el ejemplo de Cochabamba, que se sublevó en apoyo a la Junta de Buenos Aires el I4 de septiembre. Sin entrar en explicaciones doctrinarias, les advirtió que el dominio bonaerense significaba la deposición "a sus legítimos magistrados para introducir la anarquía, y vuestros tiranos os harán adorar luego a los ídolos de sus templos para que seáis la víctima de sus más torpes sacrificios" (AGI, C, 584, "Seis proclamas patrióticas de Cañete que en parte reprimieron los progresos revolucionarios del Perú”).

De generalizarse tal subordinación al Alto Perú, ello traería dos consecuencias: I) que la Audiencia charqueña caería en la órbita de una junta que estaba actuando subrogada a los principios de Bayona, lo que significaba que "la junta ejecutará con vuestros diputados ni más ni menos lo que Napoleón con los de España”, y 2) que Buenos Aires, por su conformación imperial, republicana y tiránica, no impondría una constitución uniforme sobre los demás pueblos del virreinato, sino que los esclavizaría como pueblos subalternos y reservaría "los empleos a la avaricia de los jefes aristocráticos".

El segundo pasquín de Cañete, por estar dirigido a los combatientes realistas, fue una versión resumida del anterior. Su única novedad fue la insistencia en que mientras la junta de mayo prometía a las capitales y villas sometidas que respetaría la elección de autoridades por los pueblos, en la práctica obraba de modo dictatorial: “¿Buenos Aires no ha elegido gobiernos para Córdoba y para Salta? Debéis esperar que harán lo mismo con vosotros porque no gozáis de ninguna inmunidad para ser privilegiados" (AGI, C, 584). Como bien señalara Mariluz Urquijo, Cañete utilizó en ambos pasquines su conocimiento de la desafección histórica de Charcas hacia Buenos Aires para intentar "atizar la discordia fomentando el espíritu localista que él sabía tan vivo" ("El fidelismo” I88). 
En su pasquín "Aviso al público", firmado en enero de i8II, se dirigió a la inquieta población tacneña a modo de un cronista y puso en su conocimiento noticias como el triunfo en España del "mayor general del mundo", el marqués de la Romana, sobre las tropas napoleónicas, el bloqueo portuario de Buenos Aires que le implicaba "pasar más estrecheces que Troya", el fracaso de la expedición autonomista al "inmortal Paraguay" y al Alto Perú, que "vomita el sagrado furor de su lealtad como el Vesubio sus betunes", y, finalmente, el retorno del fidelismo a "Caracas [que] llora arrepentida".

Tales noticias, en su mayoría exageradamente triunfalistas y hasta falsas, lo llevaron a arengar al público más escéptico del siguiente modo paternalista: "Americanos honrados: volved a vuestro nido; dejad los desiertos en que os habéis descarriado: buscad con tiempo la casa de vuestro padre que nunca es tarde para el que se arrepiente de veras" (AGI, C, 584). El lenguaje ilustrado de Cañete, de desprecio a la participación política del "populacho", se hizo traslucir en este pasquín y no conllevaba más remedio que el sometimiento del pueblo a la voluntad de sus auténticas autoridades absolutistas.

También en enero de i8II Cañete hizo circular en Tacna el manuscrito "Reflexiones patrióticas para desengaño de los incautos". En esta ocasión, el texto se concentró en resaltar la principal diferencia entre la eclosión juntista de i808 en la península ibérica con la ocurrida en I8Io en el Virreinato del Río de la Plata. No tuvo ninguna duda en resaltar el altruismo de la primera, en contraste con el egoísmo "cismático" del segundo:

[...] deberéis confesar de grado o fuerza que si ha sido un heroísmo en Espańa su resistencia varonil entre las dos extremidades de vencer o morir, es por el contrario un entristecido abatimiento haber jurado obediencia sumisa a un gobierno subversor al punto mismo de avanzar el peligro por solo el vergonzoso pretexto de una afectada indefinición. (AGI, C, 584)

Si bien Cañete concedió a la Revolución de Mayo el beneficio de la duda en cuanto a su pregonada lealtad a la monarquía, al parecer defendida así por una parte de la población tacneña, rotundamente descalificó los medios utilizados para lograr esa finalidad:

[...] suponed como gustáis que Buenos Aires no tiene más fin que defender la causa y los derechos de Fernando. Desde luego es un fin santo considerado en sí mismo. Pero no veis que para conseguirlo se han valido de sacrilegios, atentados enormes, deposición de magistrados, de 
tumultos, de seducción atropellando las leyes divinas y humanas? Acaso la virtud puede aconsejar jamás el uso de medios ilícitos y violentos para obtener un fin justo y noble? (AGI, $C, 584$ )

El tono de este mensaje se correspondía con aquel del ilustrado que descalificaba como un utilitarismo fallido para la unidad y supervivencia de la monarquía lo ocurrido en Buenos Aires.

Sin duda, el pasquín más significativo de Cañete durante su etapa como exiliado en Tacna fue el "Catecismo real patriótico", que en vida no pudo publicar8. Su propósito fue combatir al Catecismo público para la instrucción de los neófitos o recién convertidos al gremio de la Sociedad Patriótica que un autor anónimo redactó en Santiago de Chile y luego se publicó en Buenos Aires. Este escrito había justificado la formación de juntas de gobierno en América del Sur como en España y, tácitamente, demandaba su aplicabilidad en Chile, a imitación de Buenos Aires, para garantizar la fidelidad al monarca. En el Catecismo público, a la pregunta de un padre a su hijo: “¿Qué es junta?”, este responde: "Unos hombres buenos elegidos por sus ciudadanos para defender la pureza de la religión y los derechos del rey, y las vidas y propiedades de los vecinos".

A la pregunta "¿Y cuál es el gobierno digno de nuestra confianza?", se responde: "El mismo que el de España”. A la pregunta “¿Cuál es el gobierno de España?”, se responde: "La Junta”. Por último, a la pregunta “iPues la junta es buena?", se responde: "Sí padre buena, y muy buena porque de no en España, ni la hubiera ni la mandara”. El Catecismo, además, identificó a los que declamaban contra la adopción del juntismo como "aquellos infelices que olvidando la religión de nuestros Padres desean entronizar en estos dominios a Napoleón, y defienden entre nosotros la Anarquía y divisiones intestinas para que seamos una débil presa en sus garras" ("Catecismo público" 253-260). Contra este razonamiento del autonomismo hispanoamericano enfilaría Cañete en su particular catecismo fidelista.

El "Catecismo real patriótico" obligó a Cañete a retomar su credo doctrinario sobre la obediencia debida del pueblo en la historia de la monarquía espańola, que desarrolló como justificante en sus escritos en los que se opuso a las juntas de Montevideo y Buenos Aires. Mariluz Urquijo opina que en este catecismo Cańete "ofrece un desarrollo más cercano al pacto suareciano que a la 
doctrina política propia del despotismo ilustrado" (Mariluz, "El fidelismo" 194). En realidad, Cañete utilizó el pactismo suareciano, pero para justificar una forma de gobernar por parte de los Borbones similar a los monarcas godos de la época medieval. A la pregunta del padre a su hijo sobre si considera que el pueblo concedió la soberanía a don Pelayo, este responde que sí lo constituyó en soberano absoluto, pero "sin reservar el pueblo para sí cosa alguna del dominio eminente integro de la Corona".

La única ley fundamental surgida de ese pacto es que el rey lo puede hacer todo sin el consentimiento del pueblo, porque su dominio se estableció por derecho de conquista. En ningún pasaje del "Catecismo real patriótico" se justifica la retroversión de la soberanía al pueblo. Ante la pregunta del padre sobre si el pueblo tiene parte alguna en el gobierno del reino constituido en I809, el hijo responde que no, ya que la reacción popular de la nación "no hace más que poner un remedio provisorio" con su reconocimiento a una regencia que debe gobernar en nombre del monarca. El único caso contemplado por Cañete (que hace las veces de hijo) en el cual el pueblo podría asumir la soberanía sería cuando "se extinguiere la estirpe Real que tiene el derecho al reino, el pueblo podrá entonces elegir su gobierno conforme al derecho originario de todas las Naciones" (AGI, C, 584, "Catecismo real patriótico", f. I).

En su "Catecismo" Cañete justificó la actuación de las juntas de gobierno en la península ibérica porque ninguna se asumió como representante única del soberano, en la medida en que cada provincia era un miembro de todo un cuerpo de nación. En cambio, consideró que la Junta bonaerense violó ese principio porque, como provincia, "nada más tiene que otra provincia de España”. De ahí que en su rechazo más contundente al Catecismo público el hijo respondiera a su padre que este era un documento cismático porque "las juntas que no reconocen dependencia al Consejo de Regencia no conservan la unidad del gobierno ni son sostenidas en un mismo centro del poder público y por este vicio son propiamente unas corporaciones antipolíticas" (AGI, C, 584, "Catecismo real patriótico", f. I).

El contenido de las últimas preguntas y respuestas del "Catecismo" de Cañete no hicieron más que resaltar la falsedad en que incurría el Catecismo público al defender que el autonomismo era beneficioso para el pueblo. Fiel a la línea argumentativa contrarrevolucionaria de sus escritos de I808 y i8Io, Cañete respondió que una junta que había "abolido un virrey para establecer cinco virreyes" en su conducción no podía ser beneficiosa, como tampoco lo era democratizar la política incorporando al pueblo en la toma de decisiones:

$\begin{array}{llllllllllllllllllll}\mathbf{F} & \mathbf{R} & \mathbf{O} & \mathbf{N} & \mathbf{T} & \mathbf{E} & \mathbf{R} & \mathbf{A} & \mathbf{S} & d e & l a & \mathbf{H} & \mathbf{I} & \mathbf{S} & \mathbf{T} & \mathbf{O} & \mathbf{R} & \mathbf{I} & \mathbf{A}\end{array}$

VOL. 23, N. 1. PP. 68-96, ENERO-JUNIO DE 2018

83 
¿Cómo ha de ser a beneficio de los hombres una junta que ha exaltado a la plebe para que en sus tumultos imponga la ley a las ciudades persiguiendo a cuantos no son de su facción lo mismo que practicaban los fanáticos sectarios de Mahoma? (AGI, C, 584, "Catecismo real patriótico", ff. 3-4)

En este contexto, el pensamiento ilustrado de Cañete siguió siendo reacio a las simpatías con que el anónimo autor del Catecismo público, y quienes en la época redactaron otros textos similares, asumieron la defensa de la eclosión juntera como el modo idóneo para la transformación de los vasallos en vecinosciudadanos en Hispanoamérica (Irurozqui, “La 'evangelización’ política”).

Al tener conocimiento del estallido de la Revolución de Mayo, el virrey Abascal incorporó al Perú las provincias de la Audiencia de Charcas el i3 de julio de I8ıo, por previa petición expresa de los oidores charqueños y del presidente Vicente Nieto. Unos meses después puso al ejército realista nuevamente al mando del brigadier Goyeneche para combatir a la Expedición Auxiliadora al Perú liderada por Castelli. Pero este escenario se complicó con la revolución que estalló en Cochabamba el I4 de septiembre de i8ro y que se hizo extensiva a Oruro el 6 de octubre de ese mismo año. Ambas juntas surgieron en apoyo a la causa bonaerense. Las tropas realistas que partieron del Perú para debelarlas experimentaron una severa derrota, primero, ante las fuerzas de Castelli y Balcarce en Suipacha el 7 de noviembre de I8ıo y, luego, ante las tropas cochabambinas en Aroma el is de noviembre de i8ro.

Las tropas de Abascal se replegaron al Perú para reabastecerse. Fue en el marco de reorganizar una nueva ofensiva al Alto Perú que se volvieron a cruzar las trayectorias de Goyeneche y Cañete, esta vez no solo como amigos y confidentes, sino en el común papel de combatientes por la causa del rey. Por carta, aquel demandó a este incorporarse a su ejército acantonado en el cuartel general que se encontraba a orillas del río Desaguadero (Puno). En febrero de I8II el ilustrado asunceño aceptó el reto de tomar las armas para defender la causa realista en el Alto Perú. Con el visto bueno del virrey, Cañete se convirtió en asesor de Goyeneche que, según sus palabras, "fue lo mismo que constituirlo por un Inspector de Vigilancia, por medio de su doctrina y escritos públicos en contraposición a los impresos y papeles incendiarios que habían publicado y seguían publicando los de Buenos Aires" (AgI, C, 584, "Pedro Vicente Cañete haciendo relación de sus esfuerzos por la causa realista, I8I3”).

¿Qué papel podía representar un súbdito dotado de un amplio conocimiento doctrinario dentro del ejército realista? Cañete entendió que su actitud debía 
asemejarse a la de un propagandista de la causa para contrarrestar al enemigo, incluso en escenarios distintos a los campos de batalla. Su primer combate, paradójicamente, lo libró contra un antiguo aliado en la crisis que derivó en el establecimiento de la Junta de Gobierno de La Plata en mayo de i8o9 y que como él fue acusado de carlotista: el arzobispo Benito María Moxó y Francoli. Sucede que el I3 de noviembre de I8Io, al ser ocupada la capital charqueña por el ejército de Castelli, las autoridades de la Audiencia se vieron obligadas a reconocer a la Junta de Buenos Aires.

El arzobispo fue uno de los firmantes del acta de adhesión y "reconoció a un gobierno que seguramente creía de sospechosa legalidad" (Vargas 36). Pero la actuación más polémica de este sacerdote se produjo el 6 de enero de i8II, cuando pronunció una homilía en la catedral en presencia de Castelli, elogiosa del "valiente ejército auxiliador" triunfador en la batalla de Suipacha. Esta fue reproducida un mes después en la Gaceta de Buenos Aires. Este discurso, en el que Moxó en su condición de vasallo y ministro de paz implora por la liberación de Fernando VII de su cautiverio, concluye con el siguiente exordio dirigido a Castelli:

V. E. ha venido a estas provincias a restablecer la libertad civil, y fundar la concordia y fraternidad. No permita, pues, que quede entre sus leales moradores el menor rastro de las antiguas desavenencias y discordias. Después de tan desecha tormenta, sea V. E. el iris de paz para todo el Perú. ("Homilia")

Según relato de Cañete, una vez que tuvo conocimiento en Puno de esa homilía "persuasiva y verbosa que por el respeto de su autor hubiera anegado a todo el Perú en las opiniones seductivas y falsas de Buenos Aires" (AGI, D, 3, "Pedro Vicente de Cañete haciendo relación de sus esfuerzos por causa realista”), se decidió a atacarla con un escrito que firmó con el seudónimo de fray Gaspar Leal y que, posiblemente con la aprobación del virrey Abascal, pudo imprimir en Lima (Carta de fray Gaspar). En este documento, en un principio Cañete se impuso cuestionar la veracidad de la homilía y, sobre todo, que Moxó la hubiera pronunciado, pero al admitir la posibilidad de que tal autoría fuera cierta no le quedó otro calificativo para definirla que como fruto de la "extrema y vil cobardía” de una autoridad que había "prostituido su conciencia y su honor" (G. Mendoza I2I).

Moxó, al tener conocimiento de lo escrito en su contra por fray Gaspar Leal, publicó en Buenos Aires una réplica, oculto bajo el seudónimo de don 
Eulogio Ornís, en la que refrendó el sentido políticamente reconciliador de sus palabras (Cartas de don Eulogio Orniss). Esta publicación coincidió con el envío por parte del arzobispo a Castelli de un donativo de 6.000 pesos reunidos por los curas de su circunscripción para el sostenimiento de su ejército.

Sin duda, el momento más importante vivido por Cañete en su etapa como consejero de guerra de Goyeneche fue estar a su lado en la batalla de Guaqui del 20 de junio de I8II, victoria que causó el resquebrajamiento de la primera expedición rioplatense. En Oruro, donde el ejército realista estableció su cuartel general, Cañete quiso añadir a su papel de consejero y propagandista el de "cronista de la Revolución del Perú", encargo que le hizo Goyeneche en atención a su literatura y sus conocimientos, y "que al paso que ilustrará la historia de nuestra América recogerá el fruto de historiador de ella y la gratitud de mi ejército" (AGI, C, 584). Tal labor la comenzó con la redacción del parte de la batalla de Guaqui que Goyeneche aprobó y que junto con el suyo remitió al virrey Abascal' . Pero la máxima aspiración de Cañete fue redactar como testigo directo de los acontecimientos una "Memoria histórica y política de las revoluciones del Alto Perú y demás provincias del Río de la Plata”.

Cañete, confiando en la eficacia de su retórica grandilocuente, solicitó al virrey del Perú que patrocinara una suscripción pública con el propósito de financiar su obra, a la que consideraba vital para elevar los sentimientos patrióticos. Pero Abascal rechazó su ofrecimiento pues pensaba que la capital estaba cansada de las erogaciones voluntarias y que estas solo estaban contempladas para el sostenimiento de su ejército. Así, se entiende que, al conocer tal negativa, Cañete interrumpiera abruptamente la redacción de su "Memoria histórica" con estas palabras:

[...] ya estaba concluida la obra crónica si se le hubiese dispensado la escasa gratificación que solicitó para papel y amanuenses, pero la economía nimia del gobierno de Lima le obligó a suspender este último trabajo, dejando a la posteridad sin el importante conocimiento de unos hechos que en lo futuro hubieran podido servir de regla a la conducta de los pueblos. (AGI, $C, 584$ )

9 El virrey hizo constar en una nota al margen de página de su relación de gobierno que sus palabras sobre la batalla de Guaqui eran un resumen de los partes de Goyeneche, Ramírez y Cañete del 22 de junio de I8II (Abascal y Sousa 351-357). 
Cañete acompañó a Goyeneche en la batalla de Sipesipe (I3 de agosto de I8II), cuya victoria posibilitó al ejército realista ocupar Cochabamba y poner fin a su primera junta autonomista, que apenas pudo durar once meses. Goyeneche y sus tropas entraron en esta capital, según García Camba, "entre aplausos y aclamaciones, producto más bien del temor que de verdadero arrepentimiento, como comprobó no mucho después un nuevo alzamiento de la inconstante Cochabamba" (68). Cañete se atribuyó parte del mérito de una pacificación que supuso instaurar por un breve tiempo el dominio peruano sobre todas las provincias charqueñas: "[...] por cuantos pueblos fuimos ocupando convencí a sus cabildos y los reduje a los más honrosos sometimientos en virtud de mis consejos. Dirigiendo yo mismo las intimaciones, las cartas y los acuerdos por súplica de las mismas ciudades sometidas" (AGI, $D, 3$ ).

Una vez nombrado el general Juan Ramírez como presidente interino de la Audiencia charqueña, a continuación Goyeneche premió la actuación del ilustrado asunceño con su nombramiento como fiscal interino en lo civil y criminal de la referida provincia y le encomendó "la regeneración de aquel profanado tribunal [la Audiencia] para que se restableciera el orden político, y el de justicia por medio de un órgano incontrastable" (AGI, C, 584). Cañete alcanzó de este modo el anhelado puesto que le fuera esquivo durante sus ańos como asesor del presidente García Pizarro. Pero cuando se disponía a partir hacia su destino, Goyeneche dispuso que antes lo acompañara a Potosí con el propósito de hacer "averiguaciones importantísimas de sustracciones de plata pertenecientes al Rey, para represalias de intereses de los enemigos" (AGI, C, 584).

Hasta principios de mayo de I8I2 Cañete también ejerció en Potosí como juez superior de vigilancia, encargado de identificar y penar a los líderes autonomistas. Ambas tareas las combinó con la de presidente de la comisión militar encargada de gestionar la reocupación de Cochabamba, provincia que en diciembre de i8II proclamó por segunda vez su autonomía. Por último, se le nombró director

[...] de los delicadísimos negocios diplomáticos que ocurrieron sobre propuestas que hicieron en distintas ocasiones los caudillos de las tropas revolucionarias, con intención solapada de unir con su sistema a nuestro ejército y al general Goyeneche bajo de aparentes aspectos de fraternidad y de concordia. (AGI, C, 584)

En su condición de agente mediador para la pacificación, Cañete se encargó de las negociaciones con las guerrillas cochabambinas lideradas por el 
comandante Esteban Arze. García Camba señala que al producirse en el pueblo de Pocona uno de esos parlamentos entre el líder de los guerrilleros cochabambinos y Cañete, acompañado este por el conde de Vallehermoso, de modo inesperado aquellos hicieron uso de sus armas de fuego. Ello originó la batalla de San Sebastián o Queñual (24 de mayo de 18I2) que favoreció a las tropas realistas (García 76). A esta confrontación le siguió la batalla de la Coronilla (27 de mayo de I812), en la que, tras la derrota de las guerrillas, Cochabamba volvió a ser ocupada por Goyeneche, quien con la anuencia de Cañete dispuso el fusilamiento del presidente de la Junta, Mariano Antezana (Antezana y Antezana).

Se desconoce qué actitud adoptó Cañete con relación a los preceptos liberales promulgados por las Cortes de Cádiz y su aplicación en la Audiencia charqueña. Es indudable que estuvo presente en la ceremonia de juramentación de la Constitución de Cádiz en Potosí que presidió Goyeneche a principios de I8I3 (Soux). Posiblemente, su postura fue similar a la de la máxima autoridad de Lima, de acatar y cumplir resignadamente con un sistema representativo con el que no estaba de acuerdo. Lo único que se puede confirmar es su desapego de las disposiciones liberales en el caso de la abolición del tributo indígena. Cañete afirmó que la medida fue aplicada en Charcas a pesar de conllevar la merma del erario, que urgía de dichos recursos para mantener al ejército. Sin expresar modestia alguna, se atribuyó el protagonismo original de su restablecimiento encubierto como una contribución voluntaria y que, además, su idea se terminó adoptando en varias provincias del virreinato peruano:

[...] sea con el nombre de tributo o bajo de otro cualquier título, dieron el primer ejemplo los habitantes del pueblo de Toropalca, Caiza y Bartolo del partido de Porco, provincia de Potosí, ofreciendo espontáneamente por persuasión del subdelegado don Joseph Hernández Zermeño a influjo del que representa, el continuar pagando las mismas tasas de antes con el título de servicio de vasallaje, por auxiliar las urgencias notorias de la Corona: a cuya imitación fueron ejecutando lo mismo las demás provincias del Perú, con la satisfacción de que el exponente es el autor primordial. (AgI, C, 584, "Pedro Vicente Cañete haciendo relación de sus esfuerzos por la causa realista, I8I3")

El duro revés del ejército realista comandado por Pío Tristán en la batalla de Salta (20 de febrero de I8I3) posibilitó que la segunda expedición rioplatense, comandada por el general Manuel Belgrano, pasara a la ofensiva y recuperara varias provincias altoperuanas. Ante esta adversidad, Cañete recobró su retórica 
patriótica con el propósito de transmitir optimismo a las desmoralizadas tropas de Goyeneche. Su propaganda quiso insuflar a los combatientes que la guerra era una verdadera cruzada religiosa contra los "sarracenos de Buenos Aires". En otra de sus más significativas proclamas, dirigida "a los peruanos" el I2 de abril de I813, procuró inscribir la coyuntura bélica como el escenario de una lucha fratricida entre dos ángeles tutelares. En su alegoría el ángel del Perú actuaba bajo la protección de la Virgen y su representante terrenal era Goyeneche, a quien le correspondía el apelativo de Macabeo americano:

La experiencia os irá comprobando que vuestras no interrumpidas victorias que el ángel tutelar del Perú, delante de Dios, es más poderoso que el ángel defensor del Río de la Plata [...] Confiad en María Santísima de las Mercedes que no oirá jamás a los que la invocan solo de boca. Es madre del sol de justicia, y no es capaz de interceder por los sacrílegos profanadores de vuestros religiosos juramentos de fidelidad y de obediencia a vuestro rey y vuestra patria. (AGI, C, 584, "Proclamas a Cochabamba")

Esta propaganda, como era esperable, surtió escaso efecto en el ánimo derrotista de los realistas. Y Goyeneche, al advertir la situación crítica en que se hallaban sus fuerzas, optó por negociar un armisticio con Belgrano, al que asistió Cañete en calidad de plenipotenciario, que condujo al repliegue realista de Potosí. El brigadier hizo caso omiso de la orden proveniente de Lima de no perder por ningún motivo la provincia minera. Abascal se mostró contrariado al enterarse de la pérdida de Potosí y en una nota se lo hizo saber a Goyeneche, haciendo extensivo su malestar al "ofendido estilo que empleaba el general en jefe en sus oficios, con particularidad desde que los redactaba el doctor Cañete" (García 95). Por primera vez, el virrey enfiló su diana contra la influencia del abogado asunceño en el militar arequipeño y conminó a este a deponerlo. Al negarse Goyeneche a acatar esta orden, el virrey aceptó su renuncia a fines de abril de I8I3, lo que también significó el fin de la trayectoria de Cañete en el ejército realista.

Cañete expresó su contrariedad ante la decisión tomada por Abascal en su contra y rechazó haber influido en la decisión de Goyeneche de abandonar Potosí:

Pero si es muy reparable que constándolo al mismo virrey los servicios distinguidos del que expone (acaso sin ejemplar en este Perú) se hubiese avanzado a prevenir en una acta de guerra que celebró después de 
la derrota de Salta que el general Goyeneche lo separase de sí, por ser más perjudiciales que útiles las más veces los consejos de los letrados en asuntos militares; no con otro fundamento sino porque se persuadió de por sí, o por algunos falsos informes, de que se había resuelto la retirada de Potosí por dictamen del exponente [...]. (AGI, C, 584)

Pese a redactar en Cochabamba el 27 de junio de 1813 un pormenorizado alegato dirigido al virrey, en el que hizo constar sus méritos y servicios a la causa realista entre I8Io y I8I3, Cañete no consiguió revertir su apartamiento del ejército.

Empecinado en los efectos balsámicos de la propaganda antijuntista, Cañete creyó que, al dejar de ejercerla él, en adelante tal tarea debía asumirla la Iglesia católica. En vísperas de abandonar el cuartel general de Oruro, el Io de mayo de I8I3, redactó un oficio dirigido al arzobispo Moxó. Para entonces ambos personajes se habían reconciliado luego de la agria polémica sostenida en I8ro y, como resultado de ello, publicaron en Lima un folleto en el que se justificaba que los eclesiásticos denunciaran en sus iglesias a los enemigos de la causa realista (Cañete, Carta consultiva).

Esta vez, por medio de su oficio, Cañete propuso al arzobispo que debía implicarse aún más en la lucha contra la Junta de Buenos Aires "para exterminar a esos monstruos enemigos del reposo de la patria y de la iglesia". Concretamente, le solicitó que en su jurisdicción congregara al clero secular y regular para hacerle entender que debía implicarse en la divulgación de las proclamas del ejército realista entre sus feligreses. Y recomendó a Moxó que a su vez autorizara a que el clero

[...] fulmine excomuniones contra los novadores de la jerarquía, de los cánones y de la disciplina eclesiástica convenciendo clamorosamente en los púlpitos y en las calles que con prestar el juramento a esa opresora soberanía es atacada la religión en sus sacerdotes, en sus obispos y en sus sacramentos, y se prepara el camino para su eterna perdición, que no serán menester otras armas para que la religiosísima provincia de Cochabamba abjure tan iniquo sistema repulsando a sus sacrílegos inventores para no reconocer otra soberanía que la de España, ni otras autoridades que las que tiene reconocidas hasta el día. (AGI, C, 584)

Sin embargo, el arzobispo no dio ese paso, al producirse la reocupación de su jurisdicción por parte de las tropas del general Belgrano. 
Entre mediados de I8I3 y principios de I8I4 Cañete, acompañado de su familia, tuvo que refugiarse en Puno durante la coyuntura más adversa para el ejército realista en el Alto Perú. Allí, en su condición de fiscal protector, ofreció su colaboración al brigadier Joaquín de la Pezuela, flamante jefe del ejército realista, pero este no la aceptó, quizás ya prevenido por el virrey acerca de su influencia negativa sobre su antecesor. En noviembre de I8I4 las victorias realistas de Vilcapugio (I. ${ }^{\circ}$ de octubre de I8I3) y Ayohuma (I4 de noviembre de I8I3), que significó el fin de la segunda expedición militar rioplatense de Belgrano, posibilitaron que Cañete pudiera restablecerse en La Plata, donde "inicia al fin el despacho formal de su fiscalía" (G. Mendoza 53).

En su condición de fiscal interino de la Audiencia, el asunceño participó en el Real Acuerdo Ordinario de Justicia y Gobierno del I2 de noviembre de I8I4, celebrado en La Plata, que dispuso la extinción de la "constitución política, decretos y reglamentos emanados de las Cortes llamadas extraordinarias, con general reintegración a su primitivo ser y antiguo estado del sistema político y judicial del gobierno de la monarquía" (Acuerdos 720-72I).

En abril de i815, la amenaza sobre esta capital de la tercera expedición rioplatense, al mando esta vez del general José Rondeau, lo obligó a trasladarse temporalmente a Oruro. Pero, una vez derrotado este por las tropas de Pezuela en la batalla de Viluma (29 de noviembre de I8I5), Cañete retornó definitivamente a La Plata y ese mismo año demandó a las autoridades absolutistas de Madrid la concesión de la regencia en cualquiera de las audiencias de la América meridional, además de la cruz de la orden de Carlos III o la de San Juan (G. Mendoza 6o). Sin embargo, en el momento en que el Consejo de Indias decidió tomar en consideración su solicitud se produjo su fallecimiento, el 23 de enero de I816.

\section{Conclusiones}

Preferible Lima que Buenos Aires; tal podría ser la máxima para resumir la actuación contrarrevolucionaria de Pedro Vicente Cañete entre i809 y i8i5. A lo largo de este texto se ha demostrado que su objetivo fue impedir que la Junta de Buenos Aires consumara su intención de anexar la Audiencia de Charcas, bajo el postulado de que desde mayo de i8ıo se constituía en una junta única,

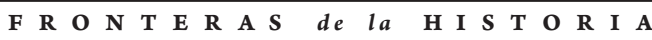

VOL. 23, N. 1. PP. 68-96, ENERO-JUNIO DE 2018

91 
suprema y depositaria exclusiva de los derechos del monarca en su condición de capital del Virreinato del Río de la Plata. Los escritos políticos doctrinarios de Cañete, desde la "Carta consultiva" de I808 al "Dictamen" de i8Io, fueron coherentes con su catecismo político de I81o y otros materiales de propaganda contrarrevolucionaria escritos en su condición de consejero de guerra del brigadier Goyeneche entre I8II y I8I3.

En todos ellos defendió que las únicas autoridades que podían ejercer la soberanía temporal en nombre del monarca eran en Espańa la Regencia y en las Indias los virreyes y los presidentes de las audiencias. En el área andina, Cañete representó al ilustrado que durante la crisis de la monarquía hispánica se mantuvo fiel al principio del regalismo absolutista que asumía la incuestionable soberanía de los monarcas hispanos por derecho de conquista sobre las Indias. De conformidad con este principio contrarrevolucionario, era inconcebible que el pueblo pudiera asumir el poder en la condición de soberano. Así lo sostuvo en su Sintagma de las resoluciones prácticas cotidianas del Real Patronazgo de las Indias de 1783 , y de la misma manera lo refrendó en sus polémicas discursivas con las autoridades juntistas de Montevideo, La Plata, La Paz y Buenos Aires.

El discurso legal y político de Cañete fue consecuente con el principio que dio coherencia al Antiguo Régimen hispano en las Indias hasta la crisis de I808. Hasta el fin de sus días, el ilustrado asunceńo se mostró convencido de que su doctrinarismo y su propaganda fueron un insumo proporcionado a los combatientes del ejército realista para evitar que la Audiencia charqueńa fuera anexada por Buenos Aires. Lo que no pudo advertir fue que su obsesión por impedir que la Audiencia sucumbiera a la tutela bonaerense constituyera, igualmente, un deseo compartido por la élite chuquisaqueña, aunque con otra motivación.

En la Audiencia de Charcas históricamente se había cultivado un sentimiento de identidad autonómica dentro de la monarquía hispánica, a pesar de depender de manera sucesiva de los virreinatos del Perú y del Río de la Plata. Para corroborarlo, basta recordar cómo los ideólogos de la identidad charqueńa, los doctores egresados de la Academia Carolina y de la Universidad San Francisco Javier, instrumentalizaron el absolutismo abanderado por el general Pedro Antonio de Olañeta entre I823 y I825 para liberarse a un tiempo de la dependencia de España, Perú y Argentina. 


\section{$\$$ \\ B I B L I O G R A F í A}

F U E N T E S P R I M A R I A S

\section{A. Archivos}

Archivo General de Indias, Sevilla, España.

Charcas (c), 584 .

Diversos (D), 3 .

\section{B. Impresos}

Acuerdos de la Real Audiencia de la Plata de los Charcas, vol. Ix. Sucre: Archivo y Embajada de España, 2007.

Cañete, Pedro Vicente. "Carta consultiva apologética de los procedimientos del Excmo. Señor Virrey don Santiago Liniers, sobre las ocurrencias de la junta de gobierno establecida en la ciudad de Montevideo”. Mallié.

---. Carta consultiva sobre la obligación que tienen los eclesiásticos de denunciar a los traidores, y exhortar en el confesionario y púlpito su descubrimiento y captura [...] que sirve de apéndice a la pastoral del Illmo. Señor Arzobispo Don Benito María Moxó. Lima: Imprenta de los Huérfanos, I8I2.

---. “Dictamen a pedimento del Excmo. Sr. Virrey”. Gaceta Extraordinaria de Buenos Aires, 3 de julio de I8ıo, pp. 4-II.

---. “'Espectáculo de la Verdad', folleto manuscrito, su autor D. Pedro Vicente Cañete, y que circuló anónimo en Chuquisaca poco después de la conmoción del 25 de mayo de r8o9". Últimos días coloniales en el Alto Perú. Documentos inéditos I808, Gabriel René Moreno. Santiago de Chile: Imprenta y Encuadernaciones Barcelona, I897.

Carta de fray Gaspar Leal sobre la homilia que el arzobispo de los Charcas don Benito María de Moxó y Francolí pronunció en su iglesia metropolitana el día 6 de enero de I8I hallándose presente el vocal de la junta de Buenos Aires don Juan José Castelli. Sin datos.

Cartas de don Eulogio Ornís a un amigo suyo en defensa de la homilia que el Illmo. Sr. Arzobispo de los Charcas pronunció en su santa iglesia metropolitana el día 6 de enero de I8II. Buenos Aires: Imprenta de los Niños Expósitos, I8II. 
"Catecismo público para la instrucción de los neófitos o recién convertidos al gremio de la Sociedad Patriótica". Mallié, pp. 253-26o.

"Homilía que el Illmo. Señor Arzobispo de los Charcas predicó en su santa iglesia metropolitana el día 6 de enero de I8II, hallándose presente el Excmo. Sr. Dr. D. Juan José Castelli, Vocal Representante de la Excma. Junta Gubernativa de las provincias del Río de la Plata". Gaceta de Gobierno de Buenos Aires, I4 de febrero de i8II.

Mallié, Augusto E., compilador. La revolución de mayo a través de los impresos de la época, t. I. Buenos Aires: Talleres Gráficos del Ministerio del Interior, I965.

“Reflexiones de Francisco Javier Elío sobre la ‘Carta consultiva apologética'...”. Mayo documental, t. vir. Buenos Aires: Universidad de Buenos Aires, I962.

\section{F U E N T ES S E C U N D A R I A S}

Abascal y Sousa, José Fernando de. Memoria de gobierno, t. II. Sevilla: Escuela de Estudios Hispano-Americanos, 1944.

Antezana, Luis y Alejandro Antezana. La segunda revolución de Cochabamba y la batalla de la Coronilla (octubre I8II-mayo I8I2). La Paz: Plural, 201 .

Bridikhina, Eugenia. Theatrum mundi. Entramados del poder en Charcas colonial. La Paz: Plural, 2007.

Buechler, Rose Marie. Gobierno, minería y sociedad. Potosí y el "renacimiento borbónico" I776-I8ro. La Paz: Biblioteca Minera Boliviana, I989.

García Camba, Andrés. Memorias para la historia de las armas españolas en el Perú, t. I. Madrid: Sociedad Tipográfica de Hortelano y Compañía, I846.

Irurozqui, Marta. "Del Acta de los Doctores al Plan de Gobierno. Las juntas en la Audiencia de Charcas (1808-1810)”. I808. La eclosión juntera en el mundo bispano, coordinado por Manuel Chust. Ciudad de México: Fondo de Cultura Económica y El Colegio de México, 2007, pp. 204-205.

---. “La 'evangelización' política. Ciudadanía, catecismos patrióticos y elecciones en Charcas (1809-I8I4)”. Debate y Perspectivas, n. ${ }^{\circ}$ 3, 2003, pp. 31-53.

---. "La telaraña de los Doctores. Charcas en el Congreso de Tucumán de i8ı6”. Prismas, Revista de Historia Intelectual, n. ${ }^{\circ}$ 20, 2016, pp. I53-г60.

Just Lleó, Estanislao. Comienzo de la independencia en el Alto Perú: los sucesos de Chuquisaca, I809. Sucre: Editorial Judicial, I994.

$94 \quad$ VOL. 23, N. 1. PP. 68-96, ENERO-JUNIO DE 2018

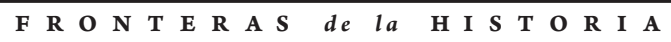


López Soldevilla, Jerónimo. "Ilustración e independencia en Nueva España. La construcción de la identidad”. Tesis doctoral, Universidad de las Palmas de Gran Canaria, 2009.

Lorandi, Ana María. "Heterogeneidad de los discursos ilustrados: funcionarios reales y eclesiásticos en el ocaso del imperio”. Estudios Bolivianos, n. ${ }^{\circ}$ I7, pp. 75-105.

Mariluz Urquijo, José María. “Estudio preliminar”. Syntagma de las resoluciones prácticas cotidianas del derecho del real patronazgo de las Indias, Pedro Vicente de Cañete. Buenos Aires: Talleres Mundial, I973, pp. 7-IIr.

---. "E1 fidelismo como elemento descentralizador". Revista del Instituto de Historia del Derecho, n. ${ }^{\circ}$ 6, 1978, pp. 179-203.

Martiré, Eduardo. "La autoridad minera en el código carolino de Pedro Vicente Cañete". Revista Chilena de Historia del Derecho, n. ${ }^{\circ}$ 6, 1970, pp. I85-199.

McFarlane, Anthony. Identity, Enlightenment and Political Dissent in Late Colonial Spanish America. Cambridge: Cambridge University Press, I998, Dor: I0.2307/3679300.

Mendoza Loza, Gunnar. El doctor Pedro Vicente de Cañete y su Historia física y política de Potosí. Sucre: Universidad de San Francisco Xavier, I954.

Mendoza Pizarro, Javier. "La Universidad de San Francisco Xavier en los sucesos de 1809 en el Alto Perú”. Revista de la Universidad Católica Boliviana, n. ${ }^{22-23}$, 2009, pp. 2I-30.

Moreno Cebrián, Alfredo. El corregidor de indios y la economía peruana en el siglo XVIII. Madrid: Consejo Superior de Investigaciones Científicas, I977.

Pérez Guilhou, Dardo. Los enemigos de la Revolución de Mayo. Buenos Aires: Academia Nacional de la Historia, 20 Io.

Portillo, José María. "Victorián de Villava, fiscal de Charcas: reforma de España y nueva moral imperial". Studia Histórica. Historia Contemporánea, n. ${ }^{\circ} 27,2009$, pp. 27-52.

---. La vida atlántica de Victorián de Villava. Madrid: Fundación Mapfre y Docecalles, 2009 .

René-Moreno, Gabriel. Últimos días coloniales en el Alto Perú. Santiago de Chile: Imprenta Cervantes, I896.

San José Vázquez, Eduardo. "Ilustración e independencia hispanoamericana: una polémica historiográfica y literaria”. Cuadernos de Ilustración y Romanticismo, n. ${ }^{\circ}$ I4, 2006, pp. 283-299.

Seiner Lizárraga, Lizardo. "Una rebelión a la deriva: fisuras y represión realista en Tacna, I8II". Abascal y la contra-independencia de América del Sur, editado por 
Scarlett O’Phelan y Georges Lomné. Lima: Instituto Francés de Estudios Andinos y Pontifica Universidad Católica del Perú, 2013, pp. 53-73.

Silva, Renán. Los ilustrados de Nueva Granada, I760-1808. Genealogía de una comunidad de interpretación. Bogotá: Banco de la República, 2002.

Soux, María Luisa. El complejo proceso hacia la independencia de Charcas (I808-I826). Guerra, ciudadania, conflictos sociales y participación indigena en Oruro. La Paz: IfEA-Plural e Instituto de Estudios Bolivianos, 2 oro.

Tandeter, Enrique. Coacción y mercado. La minería de la plata en el Potosícolonial, I692I826. Cuzco: Centro Bartolomé de las Casas, I992.

Thibaud, Clément. La Academia Carolina y la independencia de Chuquisaca (1776-I809). Sucre: Charcas y Archivo y Biblioteca Nacionales de Bolivia, 20 Io.

Vargas Ugarte, Rubén. Don Benito María de Moxó y de Francolí. Buenos Aires: Imprenta de la Universidad, I93I.

Withers, Charles. Placing the Enlightenment. Thinking Geographically about the Age of Reason. Chicago: The University of Chicago Press, 2007. 